\title{
Solution-Processed $\mathrm{Ge}_{1-\mathrm{x}} \mathrm{Sn}_{\mathrm{x}}$ Alloy Nanocrystal
}

\section{Thin Films with High Electrical Conductivity}

\section{and Tunable Energy Gaps}

\author{
Rachel C. Barbieri, ${ }^{1}$ Kai Ding, ${ }^{2} \ddot{U}$ it $\ddot{O} z g \ddot{u r},{ }^{2}$ and Indika U. Arachchige $e^{1, *}$ \\ ${ }^{1}$ Department of Chemistry, Virginia Commonwealth University, Richmond, Virginia 23284, \\ United States \\ ${ }^{2}$ Department of Electrical and Computer Engineering, Virginia Commonwealth University, \\ Richmond, Virginia 23284, United States
}

\section{Supporting Information}




\section{Slide Preparation and Functionalization}

$\mathrm{Ge}_{1-\mathrm{x}} \mathrm{Sn}_{\mathrm{x}}$ alloy NCs and QDs were spin-coated on amine-functionalized glass slides for thin film fabrication studies. Initially, a solution of TMOS $(200 \mu \mathrm{L}), 0.1 \mathrm{M} \mathrm{HCl}(70 \mu \mathrm{L})$, ethanol (400 $\mu \mathrm{L})$, and milli-Q filtered water (18 $\mathrm{M} \Omega, 70 \mu \mathrm{L})$ was stirred for 18-24 h under ambient temperature. The following day, glass slides were cut into $1 \mathrm{~cm} \times 2 \mathrm{~cm}$ pieces and cleaned via sonication in acetone, ethanol, and water for 10 min each. Next, the slides were placed in a piranha solution for $30 \mathrm{~min}$, then sonicated three times in milli-Q filtered water (18 M $\Omega)$ for 15 min each, and dried in air using $\mathrm{N}_{2}$. The TMOS solution (70 $\mu \mathrm{L} /$ slide) was immediately spin-coated (5000 rpm for $30 \mathrm{~s}$ ) onto the cleaned slides and placed in a desiccator for 18-24 h. The next day, a solution of (3mercaptopropyl)trimethoxysilane (AMINE, $600 \mu \mathrm{L}$ ), ethanol (20 mL), and milli-Q filtered water $(18 \mathrm{M} \Omega, 125 \mu \mathrm{L})$ was stirred for $90 \mathrm{~min}$ and then left undisturbed for $30 \mathrm{~min}$. Following this, the TMOS-coated slides were placed in this solution for $1 \mathrm{~h}$ for functionalization with amines. The AMINE-functionalized slides were removed, rinsed 3 times with ethanol, dried using $\mathrm{N}_{2}$, and placed in a desiccator for 18-24 h. The AMINE-functionalized slides were suspended over a $12 \mathrm{M}$ $\mathrm{HCl}$ solution for 15 min immediately before spin-coating a solution of NCs or QDs. 


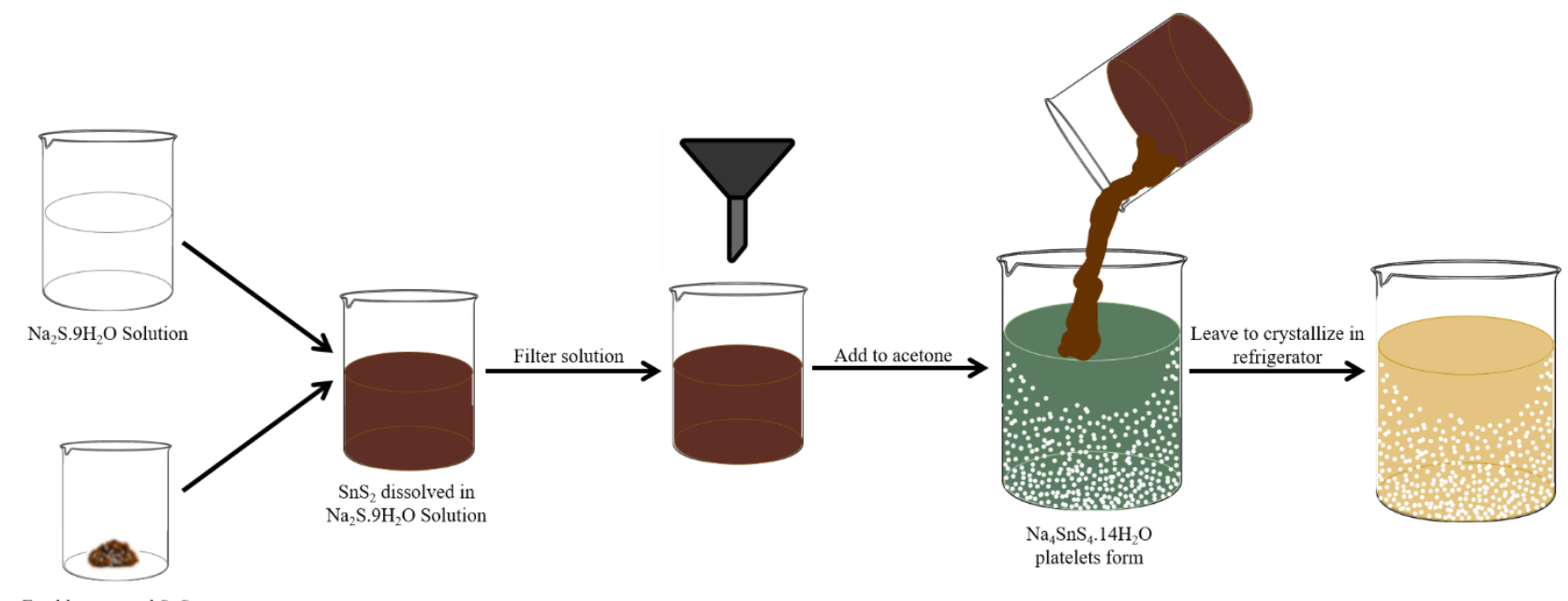

Freshly prepared $\mathrm{SnS}_{2}$

Scheme S1. A schematic illustration of the synthesis of $\mathrm{Na}_{4} \mathrm{SnS}_{4}$ (MCC ligands).

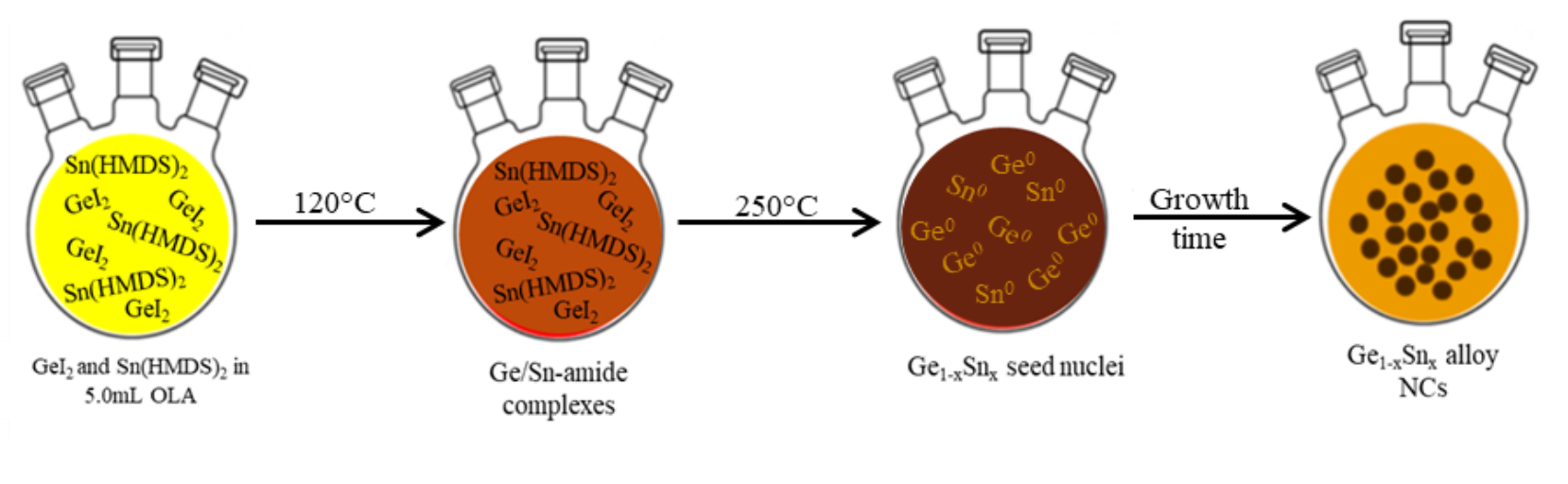

Scheme S2. A schematic illustration of synthesis of the larger $\mathrm{Ge}_{1-\mathrm{x}} \mathrm{Sn}_{\mathrm{x}}$ alloy NCs. 


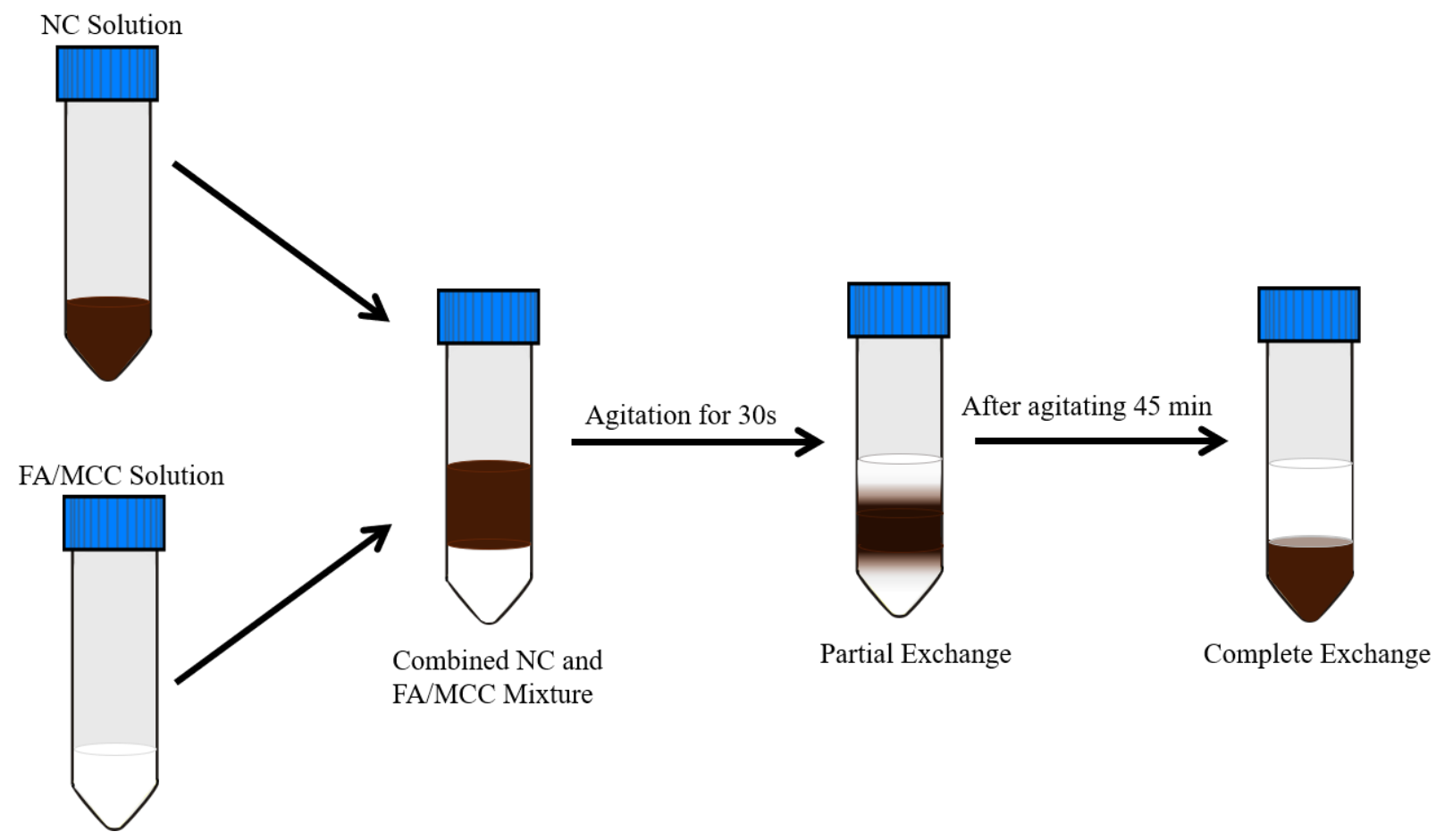

Scheme S3. A schematic illustration of the ligand exchange process for the $\mathrm{Ge}_{1-\mathrm{x}} \mathrm{Sn}_{\mathrm{x}} \mathrm{NCs}$ and QDs.

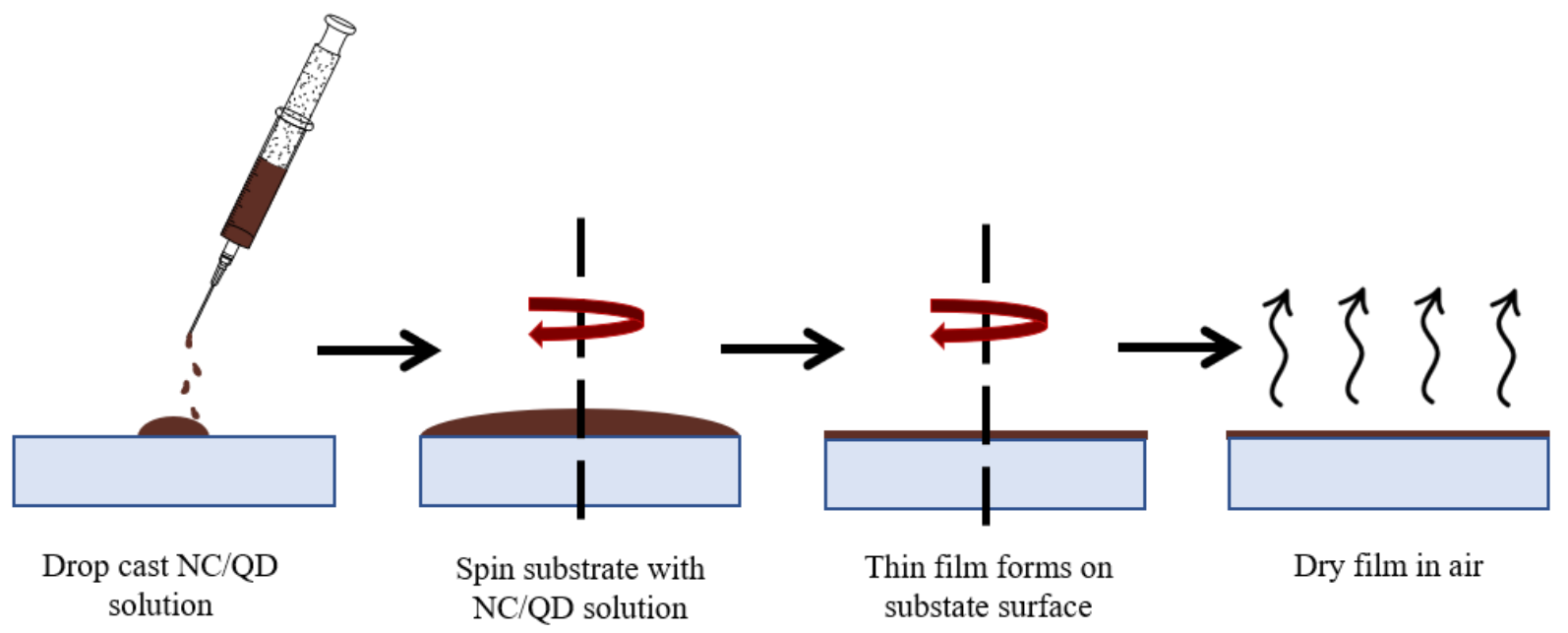

Scheme S4. A schematic illustration of the thin film fabrication process for $\mathrm{Ge}_{1-\mathrm{x}} \mathrm{Sn}_{\mathrm{x}} \mathrm{NC} / \mathrm{QD}$ films. 


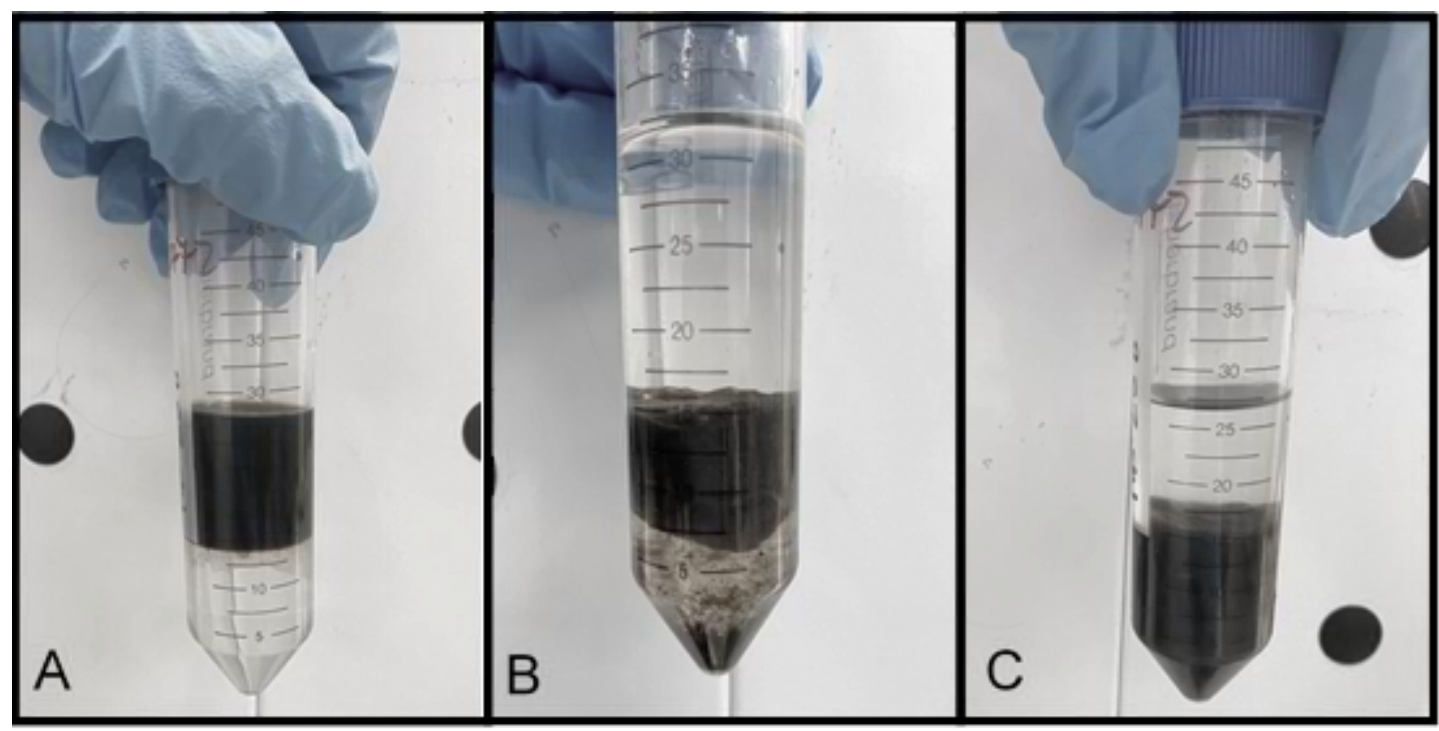

Figure S1. Photographs of each stage of the larger $\mathrm{Ge}_{1-\mathrm{x}} \mathrm{Sn}_{\mathrm{x}} \mathrm{NC}$ ligand exchange process: (A) before the exchange, (B) after partial exchange, and (C) after complete exchange. 


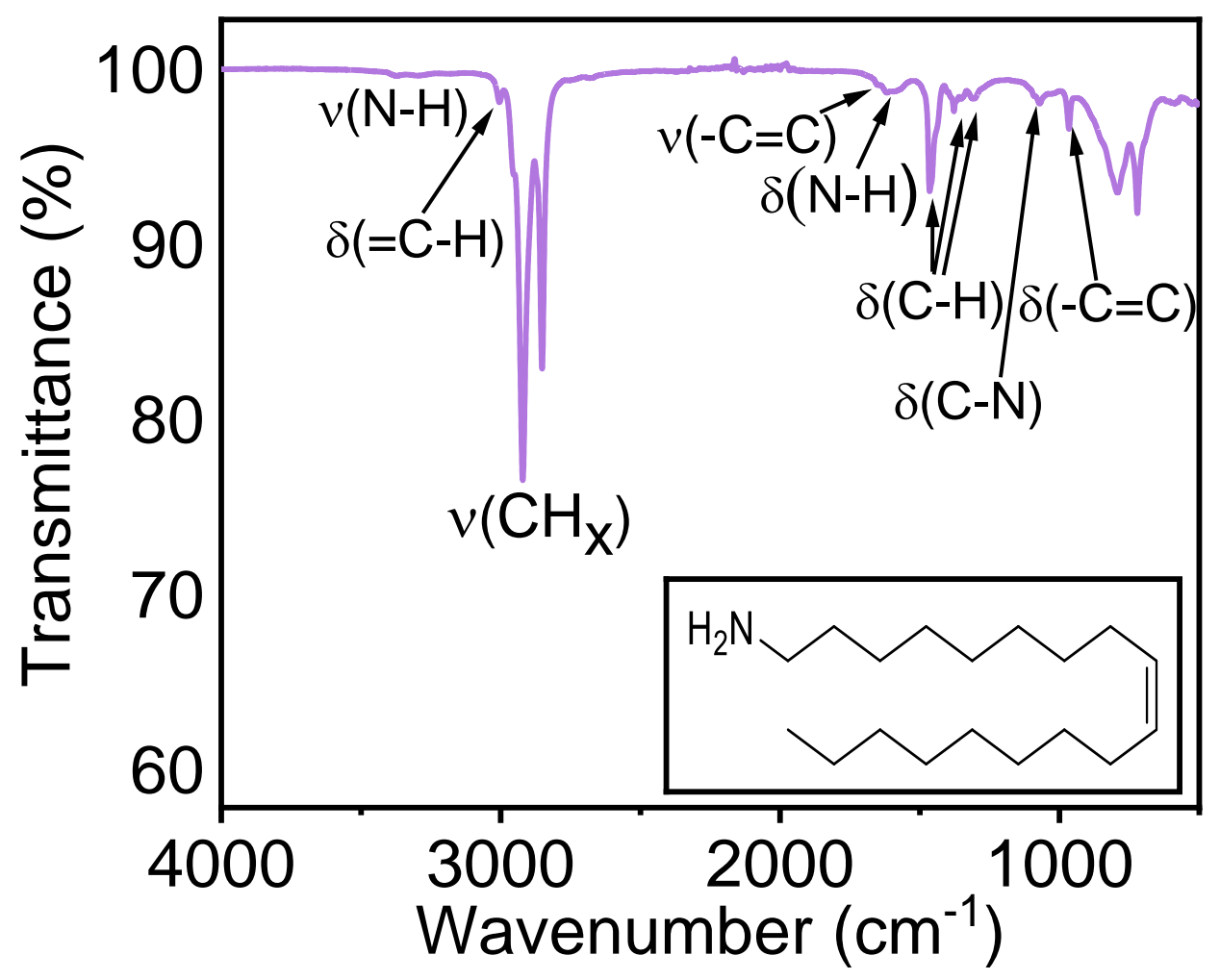

Figure S2. FTIR spectrum of 70\% OLA ligands with an inset of its molecular structure.

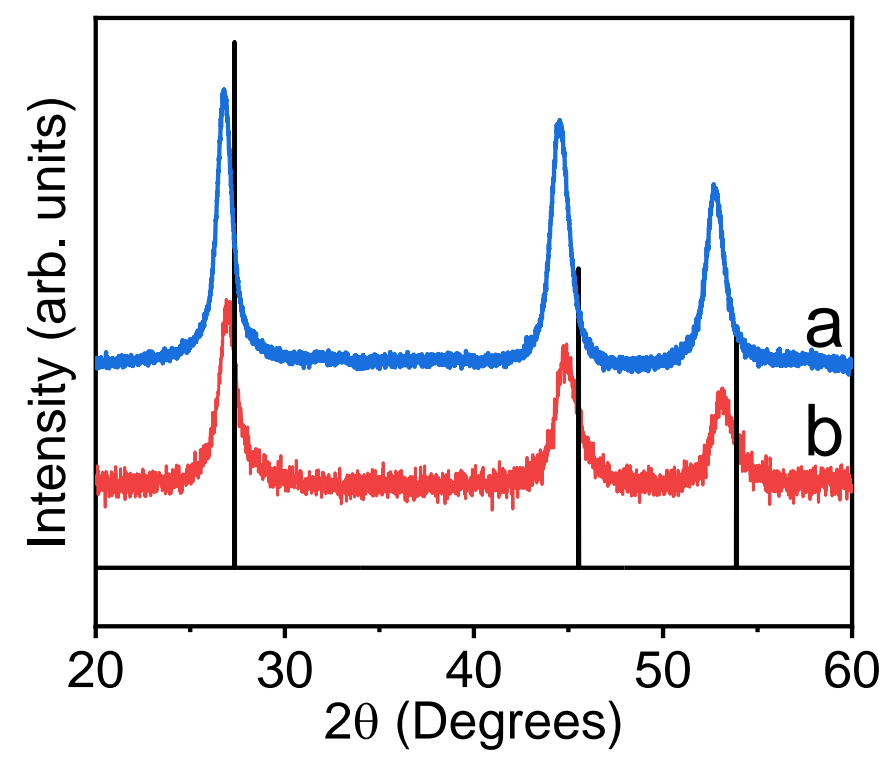

Figure S3. PXRD patterns for larger OLA-capped $\mathrm{Ge}_{1-\mathrm{x}} \mathrm{Sn}_{\mathrm{x}} \mathrm{NCs}$ : (a) $\mathrm{x}=0.10$ and (b) $\mathrm{x}=0.08$. 


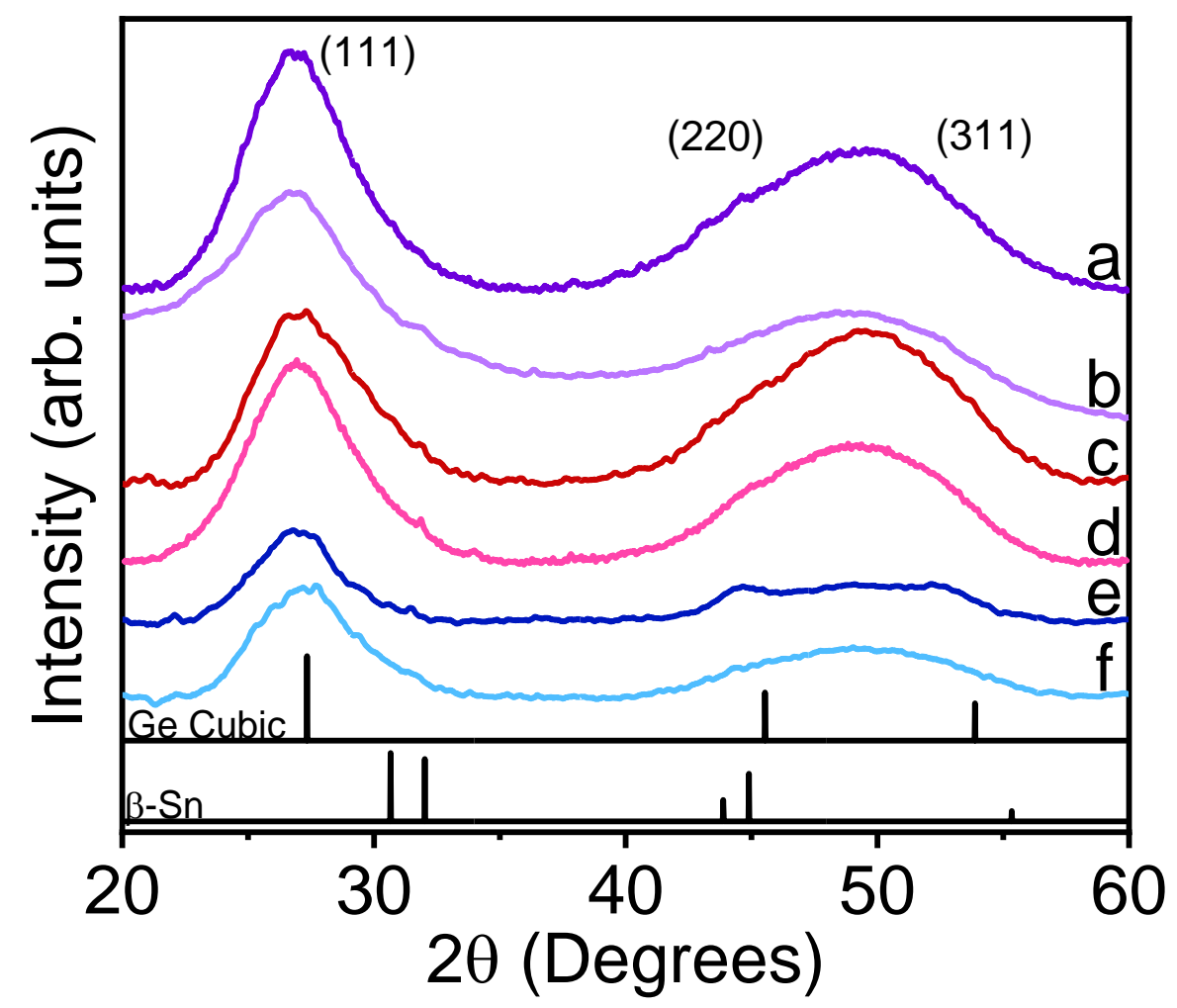

Figure S4. PXRD patterns for smaller (a) OLA-capped $\mathrm{Ge}_{0.99} \mathrm{Sn}_{0.01}$ QDs, (b) MCC-capped $\mathrm{Ge}_{0.99} \mathrm{Sn}_{0.01}$ QDs, (c) OLA-capped Ge ${ }_{0.97} \mathrm{Sn}_{0.03}$ QDs, (d) MCC-capped Ge $\mathrm{g}_{0.97} \mathrm{Sn}_{0.03}$ QDs, (e) OLAcapped $\mathrm{Ge}_{0.94} \mathrm{Sn}_{0.06}$ QDs, and (f) MCC-capped $\mathrm{Ge}_{0.94} \mathrm{Sn}_{0.06}$ QDs. The vertical lines reflect the reference pattern for cubic Ge (Ref. 00-003-0478) and $\beta$-Sn (Ref. 00-001-0731). 


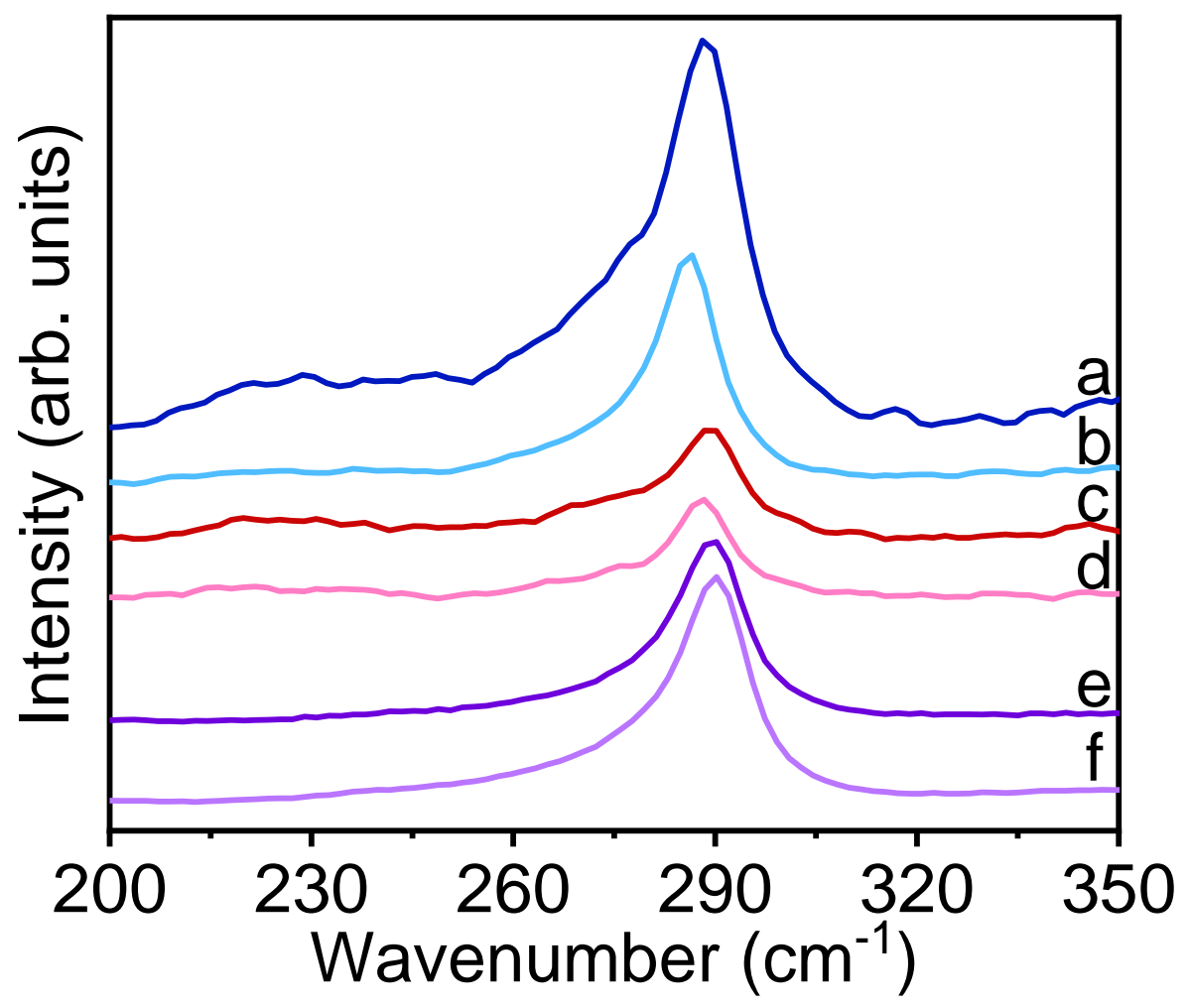

Figure S5. Raman spectra for smaller (a) OLA-capped $\mathrm{Ge}_{0.94} \mathrm{Sn}_{0.06}$ QDs, (b) MCC-capped $\mathrm{Ge}_{0.94} \mathrm{Sn}_{0.06}$ QDs, (c) OLA-capped Ge ${ }_{0.97} \mathrm{Sn}_{0.03}$ QDs, (d) MCC-capped Ge $\mathrm{g}_{.97} \mathrm{Sn}_{0.03}$ QDs, (e) OLAcapped $\mathrm{Ge}_{0.99} \mathrm{Sn}_{0.01}$ QDs, and (f) MCC-capped $\mathrm{Ge}_{0.99} \mathrm{Sn}_{0.01}$ QDs. 
Table S1. A Comparison of the elemental compositions of OLA-coated $\mathrm{Ge}_{1-\mathrm{x}} \mathrm{Sn}_{\mathrm{x}}$ alloy QDs obtained from XPS and SEM/EDS analyses. Spectra were acquired from three spots from each sample for the XPS analysis, five spots from each sample for the SEM/EDS analysis, and the average atomic compositions are presented.

\begin{tabular}{|c|c|c|c|c|}
\hline \multirow{2}{*}{$\begin{array}{c}\text { Nominal } \\
\text { Composition }\end{array}$} & \multicolumn{2}{|c|}{ XPS Compositional Analysis } & \multicolumn{2}{c|}{ EDS Compositional Analysis } \\
\cline { 2 - 5 } & $\mathrm{At} \% \mathrm{Ge}$ & $\mathrm{At} \% \mathrm{Sn}$ & $\mathrm{At} \% \mathrm{Ge}$ & $\mathrm{At} \% \mathrm{Sn}$ \\
\hline $\mathrm{Ge}_{0.99} \mathrm{Sn}_{0.01}$ & 99.0 & 1.0 & 98.8 & 1.2 \\
\hline $\mathrm{Ge}_{0.97} \mathrm{Sn}_{0.03}$ & 96.9 & 3.1 & 97.0 & 3.0 \\
\hline $\mathrm{Ge}_{0.94} \mathrm{Sn}_{0.06}$ & 93.7 & 6.3 & 94.2 & 5.8 \\
\hline $\mathrm{Ge}_{0.92} \mathrm{Sn}_{0.08}$ & 91.9 & 8.1 & 92.1 & 7.9 \\
\hline
\end{tabular}

Table S2. Elemental composition of $\mathrm{Ge}_{1-\mathrm{x}} \mathrm{Sn}_{\mathrm{x}} \mathrm{NCs}$ and QDs before and after the MCC ligand exchange. Data were obtained from SEM/EDS analysis of five individually prepared samples and the average values are presented.

\begin{tabular}{|c|c|c|c|}
\hline $\begin{array}{c}\text { Nominal } \\
\text { Size }\end{array}$ & $\begin{array}{c}\text { Nominal } \\
\text { Composition }\end{array}$ & $\begin{array}{c}\text { Experimental Sn Composition } \\
(\%), \text { Before Ligand Exchange }\end{array}$ & $\begin{array}{c}\text { Experimental Sn Composition } \\
\text { (\%), After Ligand Exchange }\end{array}$ \\
\hline$\sim 10 \mathrm{~nm}$ & $\mathrm{Ge}_{0.92} \mathrm{Sn}_{0.08}$ & $7.1 \%$ & $9.6 \%$ \\
\hline \multirow{5}{*}{$\sim 5 \mathrm{~nm}$} & $\mathrm{Ge}_{0.99} \mathrm{Sn}_{0.01}$ & $1.2 \%$ & $1.6 \%$ \\
\cline { 2 - 4 } & $\mathrm{Ge}_{0.97} \mathrm{Sn}_{0.03}$ & $3.0 \%$ & $4.4 \%$ \\
\cline { 2 - 4 } & $\mathrm{Ge}_{0.94} \mathrm{Sn}_{0.06}$ & $5.8 \%$ & $6.5 \%$ \\
\cline { 2 - 4 } & $\mathrm{Ge}_{0.92} \mathrm{Sn}_{0.08}$ & $7.9 \%$ & $10.1 \%$ \\
\hline
\end{tabular}




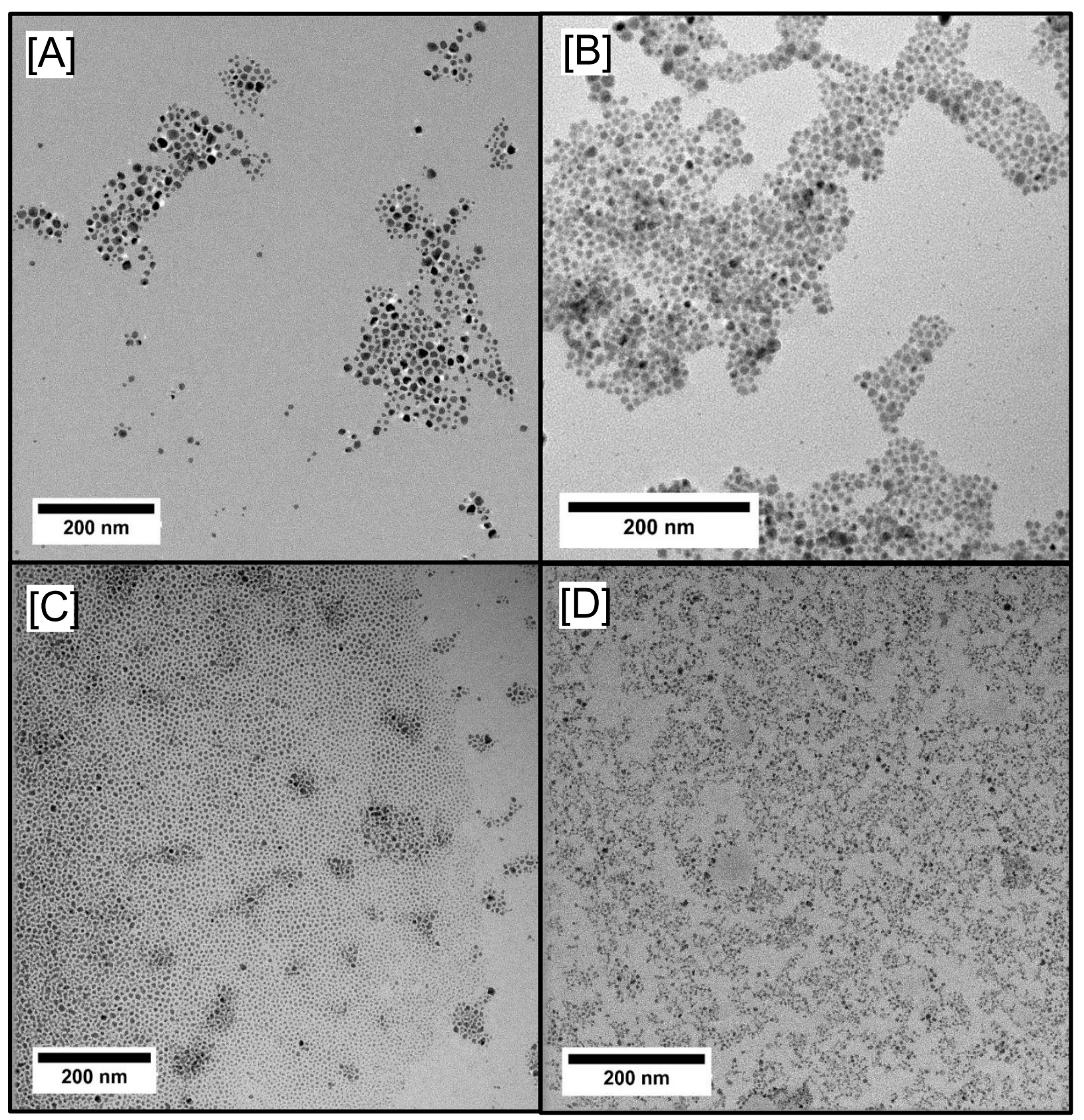

Figure S6. LRTEM images of the larger $\mathrm{Ge}_{0.92} \mathrm{Sn}_{0.08} \mathrm{NCs}(\mathrm{A})$ before and (B) after the ligand exchange. LRTEM images of the smaller $\mathrm{Ge}_{0.94} \mathrm{Sn}_{0.06}$ QDs (C) before and (D) after the ligand exchange. 

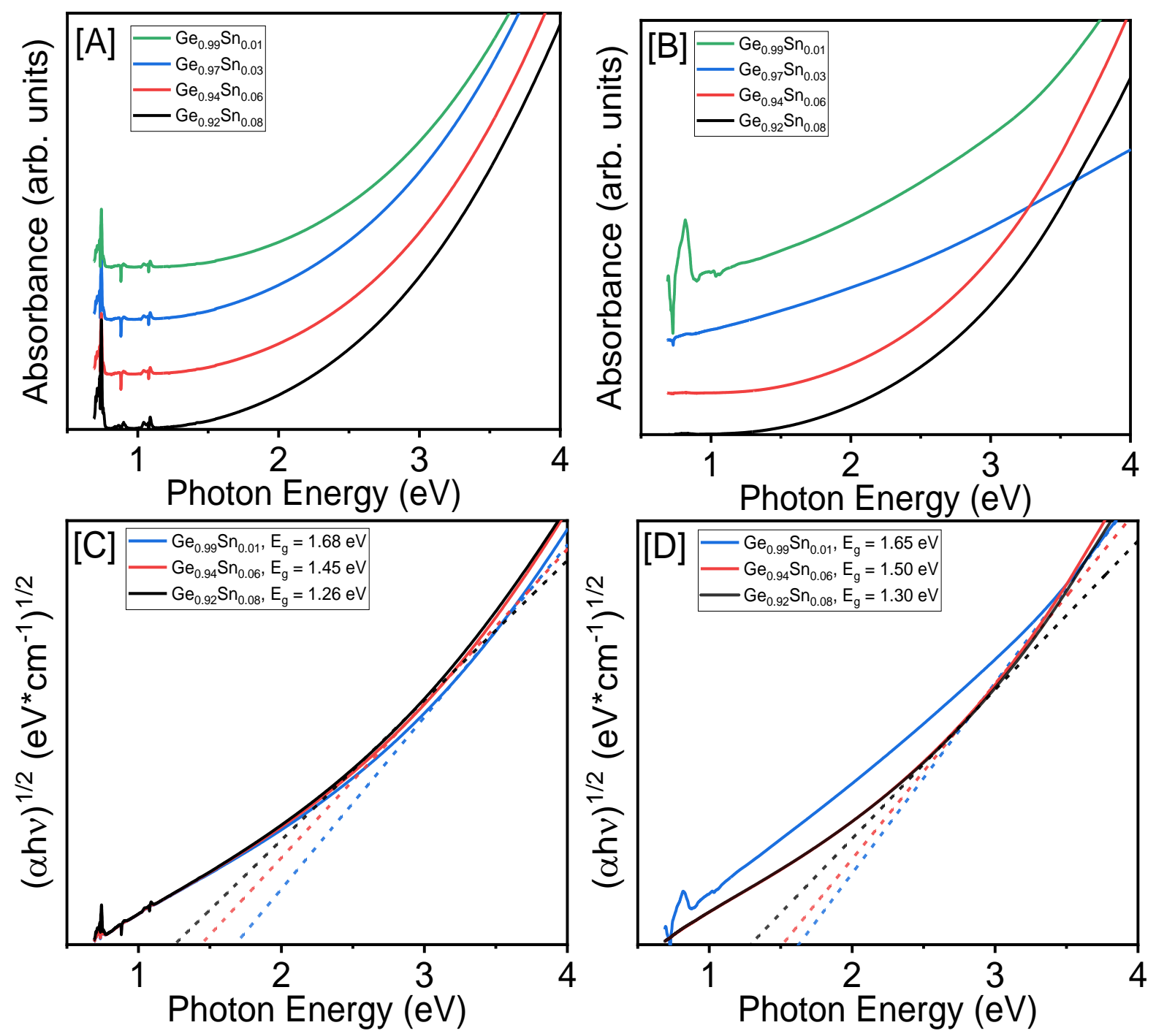

Figure S7. Solution-state UV-visible-NIR absorption spectra of $\mathrm{Ge}_{1-\mathrm{x}} \mathrm{Sn}_{\mathrm{x}}$ alloy QDs with varying Sn compositions (A) before and (B) after the MCC ligand exchange. Tauc (indirect) plots of $\mathrm{Ge}_{1-}$ ${ }_{\mathrm{x}} \mathrm{Sn}_{\mathrm{x}}$ alloy QDs (C) before and (D) after the ligand exchange. The absorption onsets were determined from the extrapolation of the linear portion of each spectrum to the energy axis. 
Table S3. Energy gaps of $\mathrm{Ge}_{1-\mathrm{x}} \mathrm{Sn}_{\mathrm{x}}$ alloy QDs estimated from solid-state absorption (KubelkaMunk) and solution-state absorption (Tauc Indirect) spectroscopy.

\begin{tabular}{|c|c|c|c|c|}
\hline $\begin{array}{c}\text { Nominal } \\
\text { Composition }\end{array}$ & $\begin{array}{c}\text { Solution State } \\
\text { Energy Gap, } \\
\text { Before } \\
\text { Exchange }(\mathrm{eV})\end{array}$ & $\begin{array}{c}\text { Solution State } \\
\text { Energy Gap, } \\
\text { After Exchange } \\
(\mathrm{eV})\end{array}$ & $\begin{array}{c}\text { Solid State } \\
\text { Energy Gap, } \\
\text { Before Exchange } \\
(\mathrm{eV})\end{array}$ & $\begin{array}{c}\text { Solid State } \\
\text { Energy Gap, After } \\
\text { Exchange (eV) }\end{array}$ \\
\hline $\mathrm{Ge}_{0.99} \mathrm{Sn}_{0.01}$ & 1.68 & 1.65 & 1.54 & 1.47 \\
\hline $\mathrm{Ge}_{0.94} \mathrm{Sn}_{0.06}$ & 1.45 & 1.50 & 1.41 & 1.30 \\
\hline $\mathrm{Ge}_{0.92} \mathrm{Sn}_{0.08}$ & 1.26 & 1.30 & 1.20 & 1.23 \\
\hline
\end{tabular}



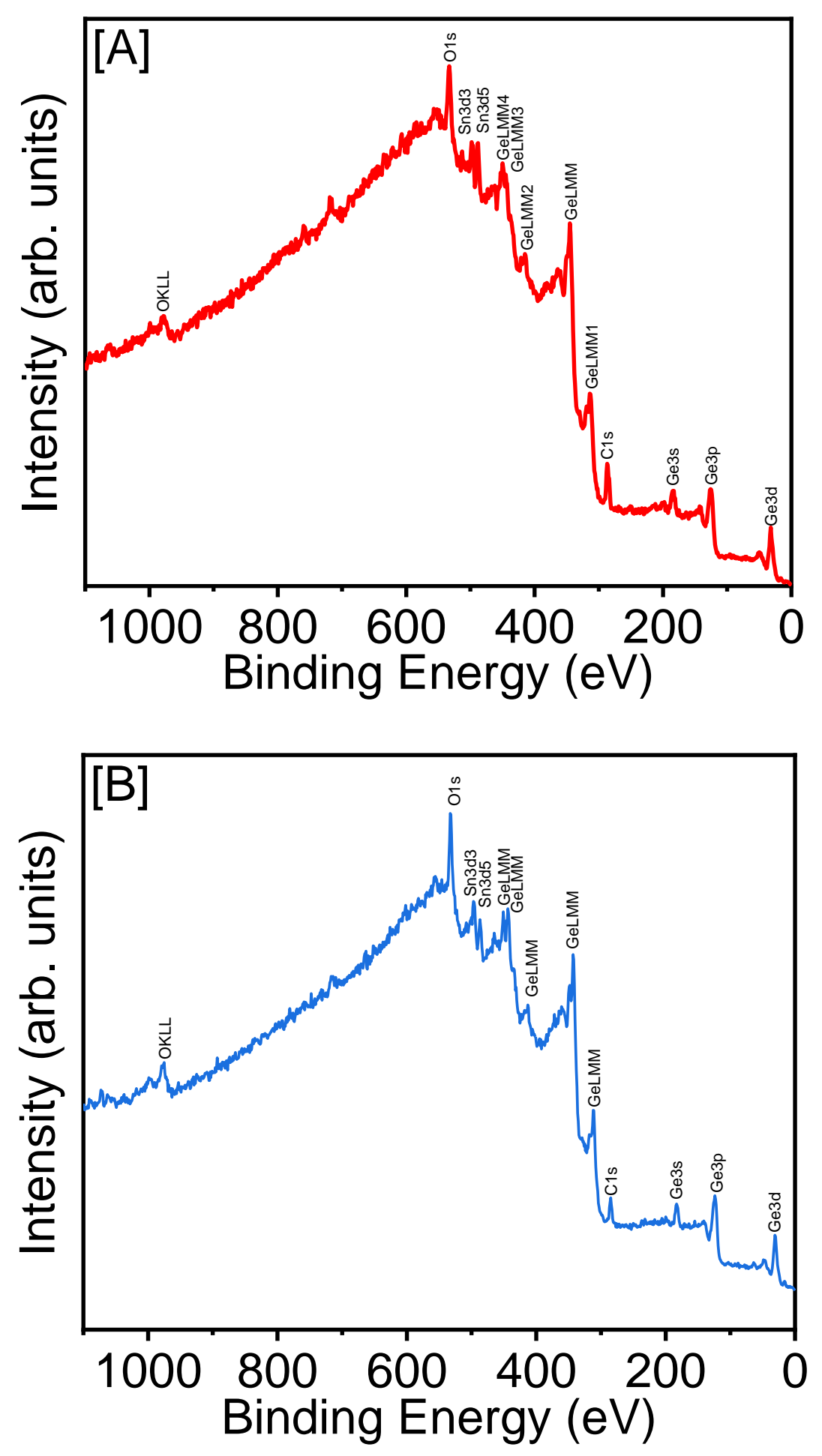

Figure S8. XPS survey scans of larger $\mathrm{Ge}_{0.92} \mathrm{Sn}_{0.08} \mathrm{NCs}$ (A) before and (B) after MCC ligand exchange. 

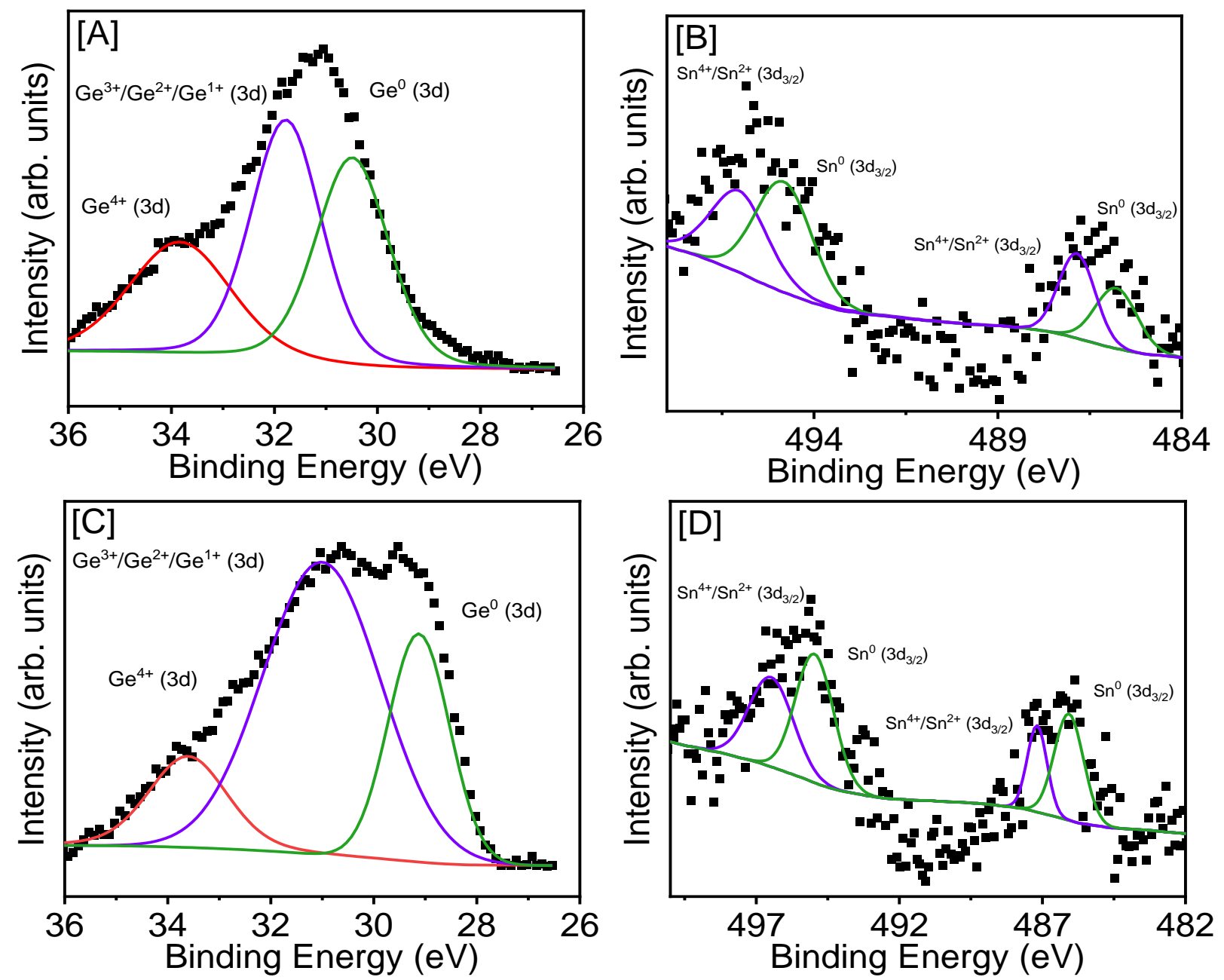

Figure S9. (A) Ge3d and (B) $S n 3 d_{3 / 2}$ XPS spectra of the unexchanged $\mathrm{Ge}_{0.99} \mathrm{Sn}_{0.01}$ QDs. (C) Ge3d and (D) $S n 3 d_{3 / 2}$ XPS spectra of the unexchanged $\mathrm{Ge}_{0.97} \mathrm{Sn}_{0.03}$ QDs. Dotted lines represent the spectral data. The green lines are fitted peaks that represent $\mathrm{Ge}^{0} / \mathrm{Sn}^{0}$ species, the purple lines are the fitted peaks that represent different oxidation states of surface species, and the red line is the suspected surface oxidation peaks. 

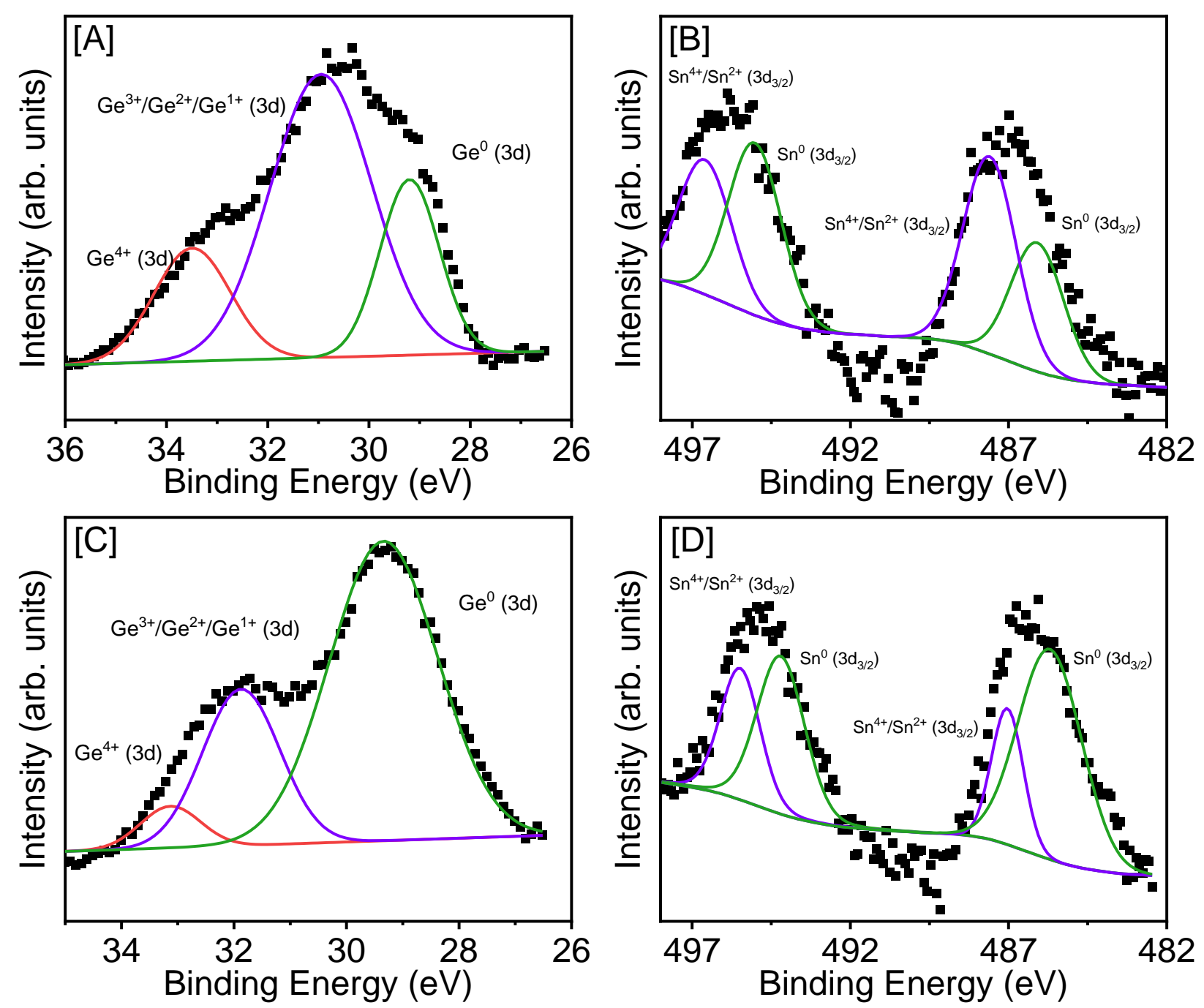

Figure S10. (A) Ge3d and (B) Sn3d $3 / 2$ XPS spectra of the unexchanged $\mathrm{Ge}_{0.94} \mathrm{Sn}_{0.06}$ QDs. (C) Ge3d and (D) $\mathrm{Sn}_{3} \mathrm{~d}_{3 / 2}$ XPS spectra of the unexchanged $\mathrm{Ge}_{0.92} \mathrm{Sn}_{0.08}$ QDs. Dotted lines represent the spectral data. The green lines are fitted peaks that represent $\mathrm{Ge}^{0} / \mathrm{Sn}^{0}$ species, the purple lines are the fitted peaks that represent different oxidation states of surface species, and the red line is the suspected surface oxidation peaks. 


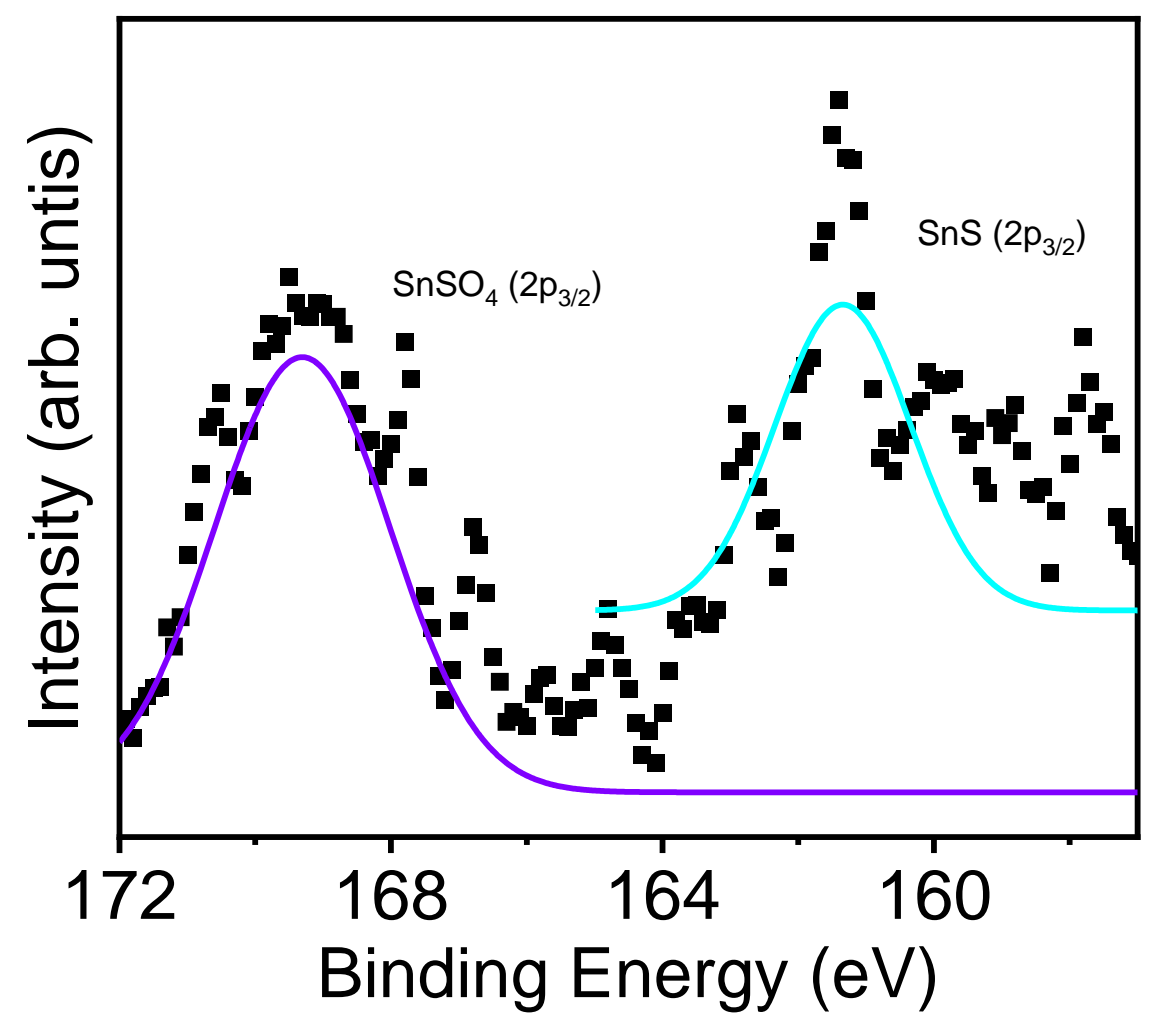

Figure S11. S 2 $p_{3 / 2}$ XPS spectrum of the MCC-exchanged larger $\mathrm{Ge}_{0.92} \mathrm{Sn}_{0.08}$ alloy NCs. Dotted lines represent the spectral data and the colored lines are fitted deconvolutions. 


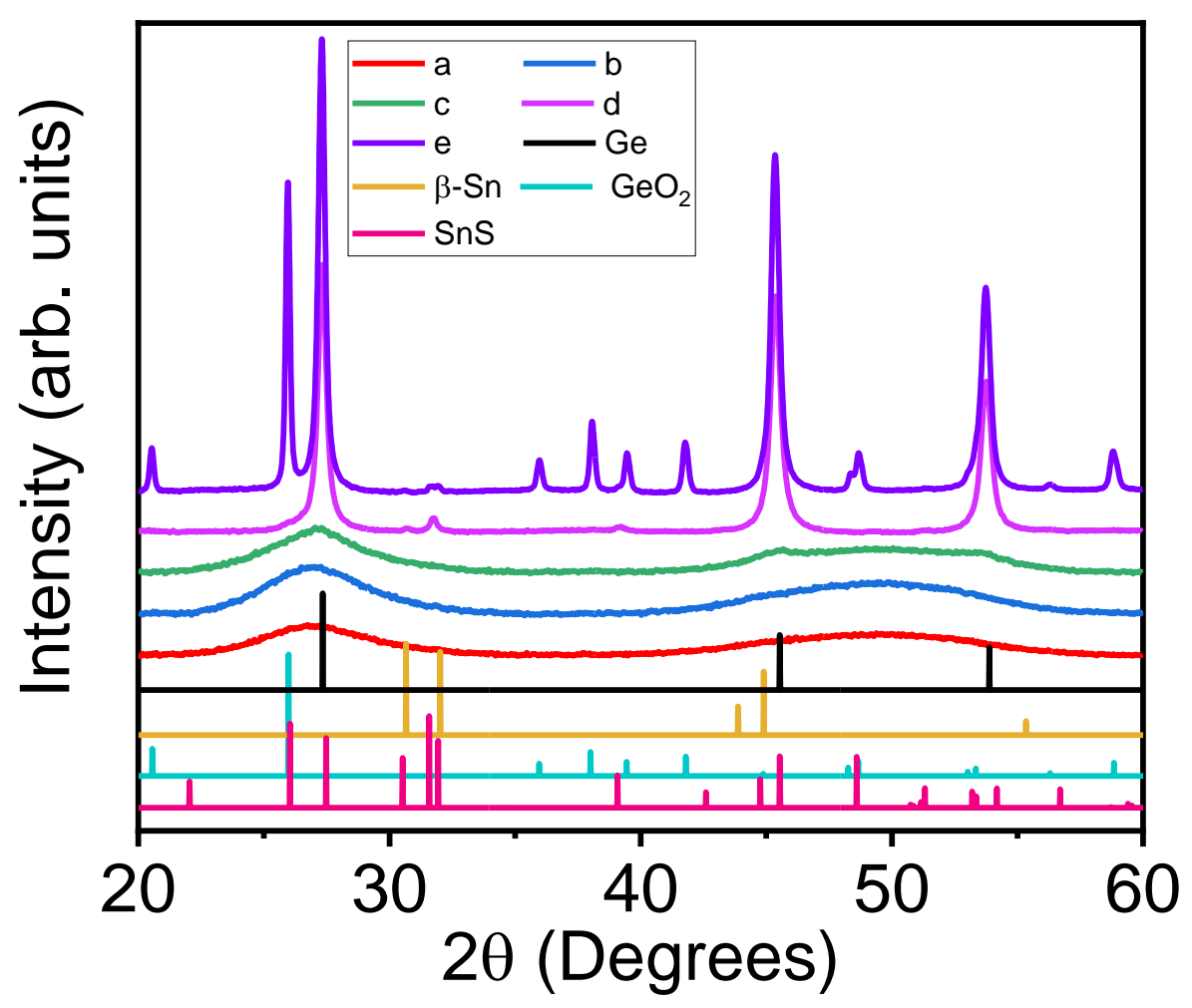

Figure S12. Air-free annealing study of the MCC-capped $\mathrm{Ge}_{0.97} \mathrm{Sn}_{0.03}$ alloy QDs monitored by PXRD: (a) as-prepared QDs at $25^{\circ} \mathrm{C}$ along with QDs annealed at (b) $200{ }^{\circ} \mathrm{C}$ for $2 \mathrm{~h}$, (c) $350{ }^{\circ} \mathrm{C}$ for $4 \mathrm{~h}$, (d) $400{ }^{\circ} \mathrm{C}$ for $4.5 \mathrm{~h}$, and (e) $500{ }^{\circ} \mathrm{C}$ for $5.5 \mathrm{~h}$. The vertical lines reflect the reference patterns for bulk cubic Ge (JCPDS 00-003-0478), $\beta$-Sn (JCPDS 00-001-0926), hexagonal $\mathrm{GeO}_{2}$ (JCPDS 00-004-0497), and orthorhombic SnS (JCPDS 04-004-3831). 


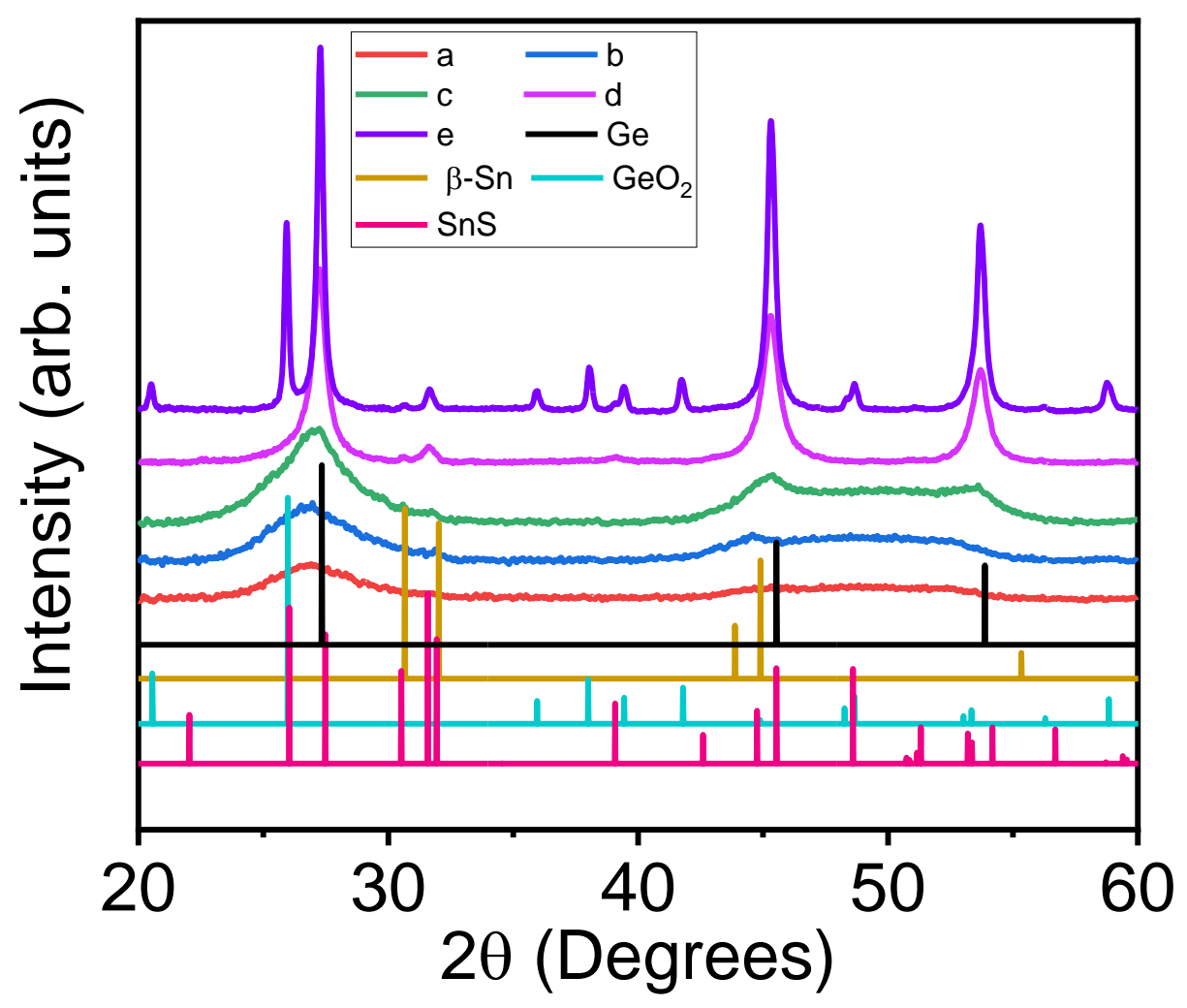

Figure S13. Air-free annealing study of the MCC-capped $\mathrm{Ge}_{0.94} \mathrm{Sn}_{0.06}$ alloy QDs monitored by PXRD: (a) as-prepared QDs at $25^{\circ} \mathrm{C}$ along with QDs annealed at (b) $200{ }^{\circ} \mathrm{C}$ for $2 \mathrm{~h}$, (c) $350{ }^{\circ} \mathrm{C}$ for $4 \mathrm{~h}$, (d) $400{ }^{\circ} \mathrm{C}$ for $4.5 \mathrm{~h}$, and (e) $500{ }^{\circ} \mathrm{C}$ for $5.5 \mathrm{~h}$. The vertical lines reflect the reference patterns for bulk cubic Ge (JCPDS 00-003-0478), $\beta$-Sn (JCPDS 00-001-0926), hexagonal $\mathrm{GeO}_{2}$ (JCPDS 00-004-0497), and orthorhombic SnS (JCPDS 04-004-3831). 


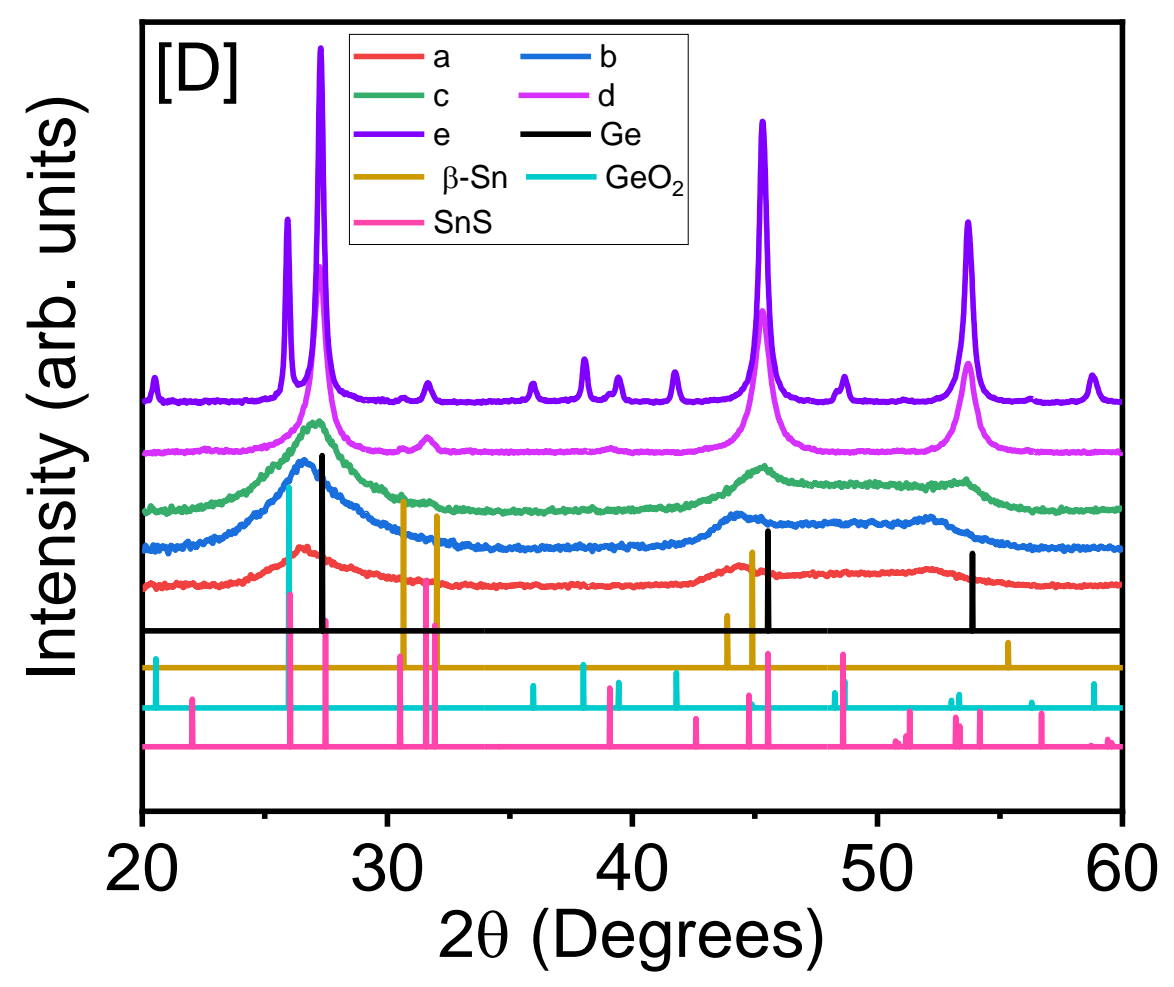

Figure S14. Air-free annealing study of the MCC-capped $\mathrm{Ge}_{0.92} \mathrm{Sn}_{0.08}$ alloy QDs monitored by PXRD: (a) as-prepared QDs at $25^{\circ} \mathrm{C}$ along with QDs annealed at (b) $200{ }^{\circ} \mathrm{C}$ for $2 \mathrm{~h}$, (c) $350{ }^{\circ} \mathrm{C}$ for $4 \mathrm{~h}$, (d) $400{ }^{\circ} \mathrm{C}$ for $4.5 \mathrm{~h}$, and (e) $500{ }^{\circ} \mathrm{C}$ for $5.5 \mathrm{~h}$. The vertical lines reflect the reference patterns for bulk cubic Ge (JCPDS 00-003-0478), $\beta$-Sn (JCPDS 00-001-0926), hexagonal $\mathrm{GeO}_{2}$ (JCPDS 00-004-0497), and orthorhombic SnS (JCPDS 04-004-3831). 


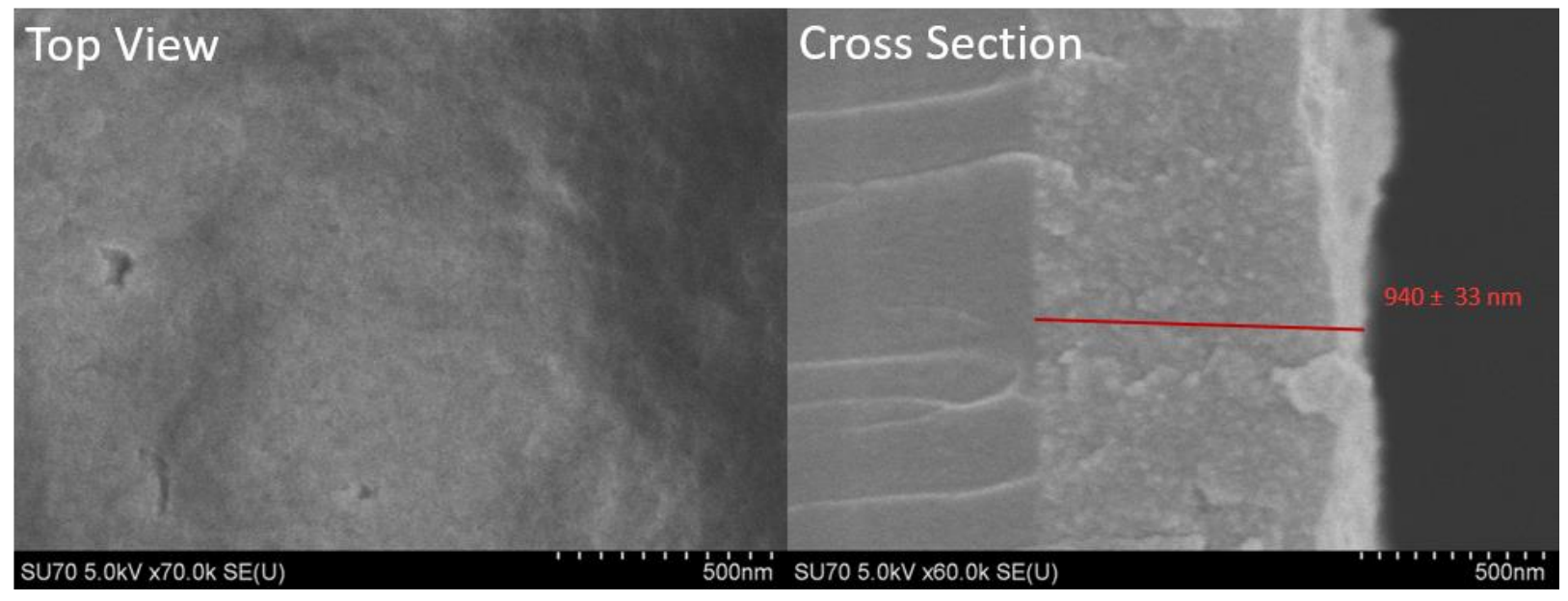

Figure S15. Top view (left) and cross section (right) view of drop cast MCC-capped $\mathrm{Ge}_{0.92} \mathrm{Sn}_{0.08}$ QD thin film with thickness measurement.

Equation S1. Relationship between conductivity ( $\sigma)$, current (I), and voltage (V) with respect to film thickness $(t)$, which is applicable when the contact width is much larger than the contact spacing, and film conductivity and thickness are uniform.

$$
\frac{\sigma \times t \times(\text { contact width })}{\text { contact spacing }}=\frac{I}{V}
$$




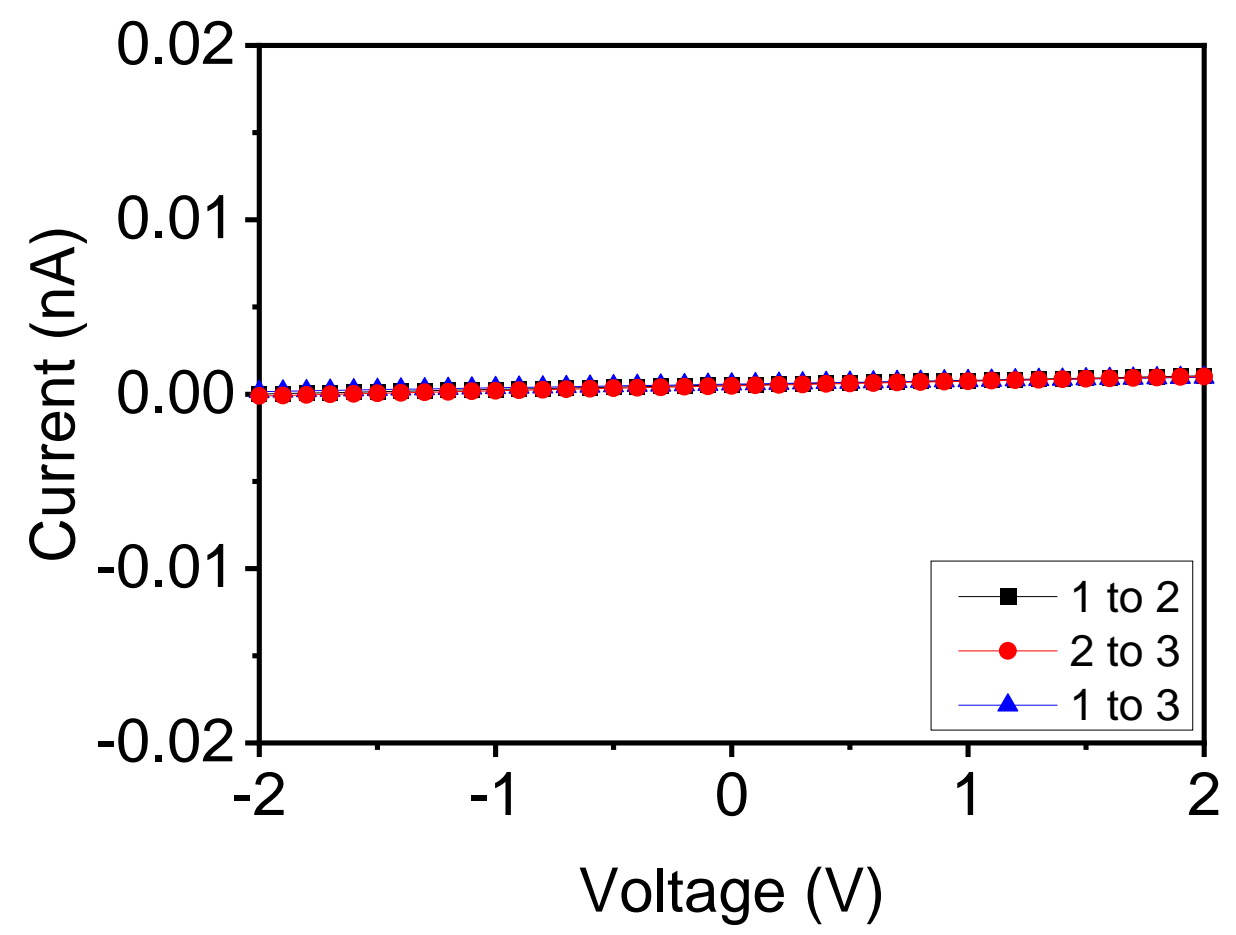

Figure S16. I-V curves across different distances for the $\sim 200 \mathrm{~nm}$ OLA-capped $\mathrm{Ge}_{0.92} \mathrm{Sn}_{0.08}$ QD thin films. 

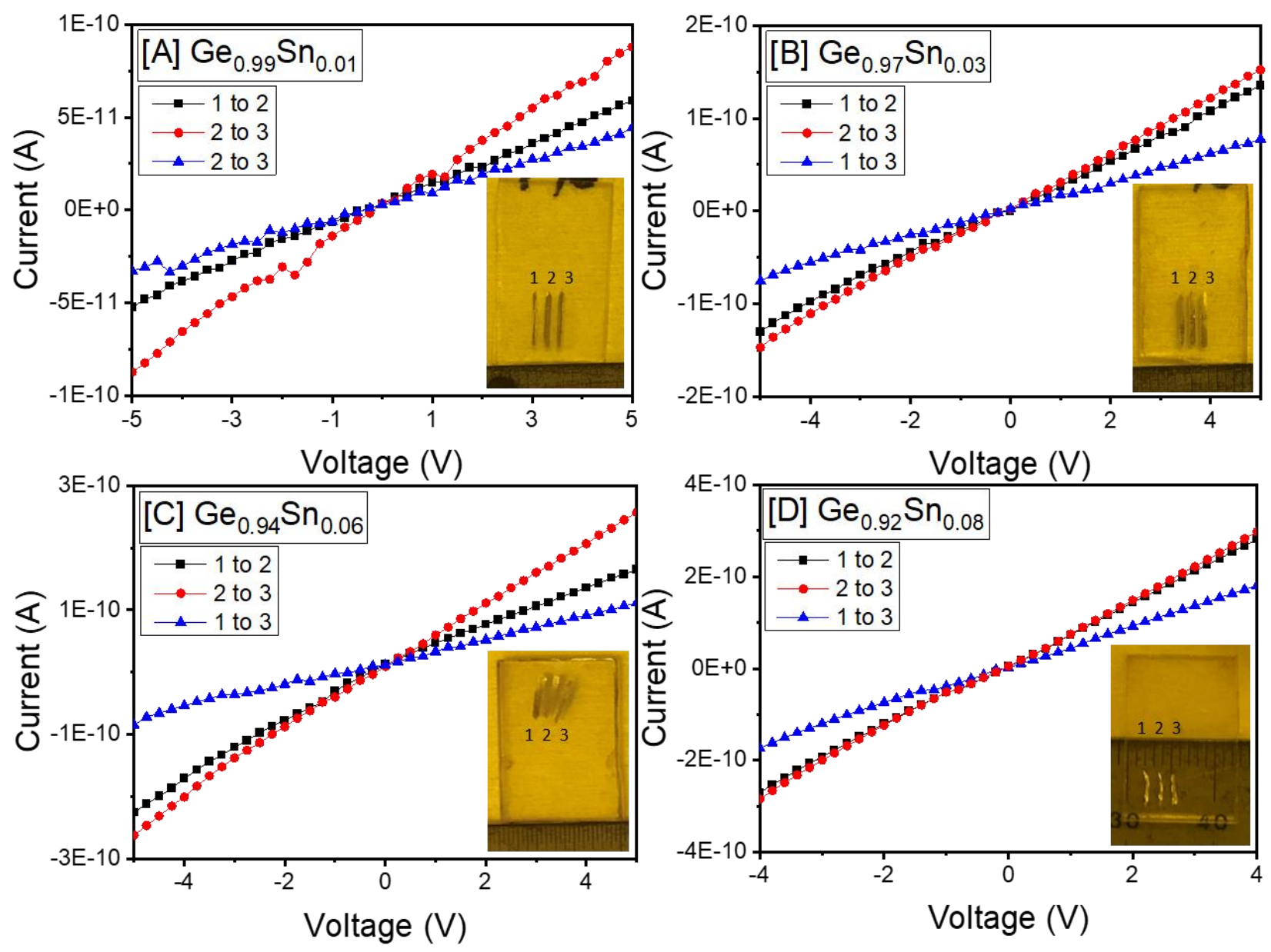

Figure S17. I-V curves across different distances for $200 \mathrm{~nm}$ MCC-capped (A) $\mathrm{Ge}_{0.99} \mathrm{Sn}_{0.01}$, (B) $\mathrm{Ge}_{0.97} \mathrm{Sn}_{0.03}$, (C) $\mathrm{Ge}_{0.94} \mathrm{Sn}_{0.06}$, and (D) $\mathrm{Ge}_{0.92} \mathrm{Sn}_{0.08} \mathrm{QD}$ thin films. Insets show each film with the indium contacts. 
Table S4. Room temperature electrical conductivity of the MCC-capped $\mathrm{Ge}_{1-\mathrm{x}} \mathrm{Sn}_{\mathrm{x}}$ alloy QD thin films. The data were recorded from three individually prepared thin film samples and the average values and standard deviations are presented.

\begin{tabular}{|c|c|c|}
\hline QD Composition & Averaged Film Conductivity $(\mathrm{S} / \mathrm{cm})$ & Standard Deviation \\
\hline $\mathrm{Ge}_{0.99} \mathrm{Sn}_{0.01}$ & $1.24 \times 10^{-6}$ & $\pm 2.69 \times 10^{-7}$ \\
\hline $\mathrm{Ge}_{0.97} \mathrm{Sn}_{0.03}$ & $1.47 \times 10^{-6}$ & $\pm 2.63 \times 10^{-7}$ \\
\hline $\mathrm{Ge}_{0.94} \mathrm{Sn}_{0.06}$ & $1.87 \times 10^{-6}$ & $\pm 1.12 \times 10^{-7}$ \\
\hline $\mathrm{Ge}_{0.92} \mathrm{Sn}_{0.08}$ & $3.49 \times 10^{-6}$ & $\pm 1.73 \times 10^{-7}$ \\
\hline
\end{tabular}

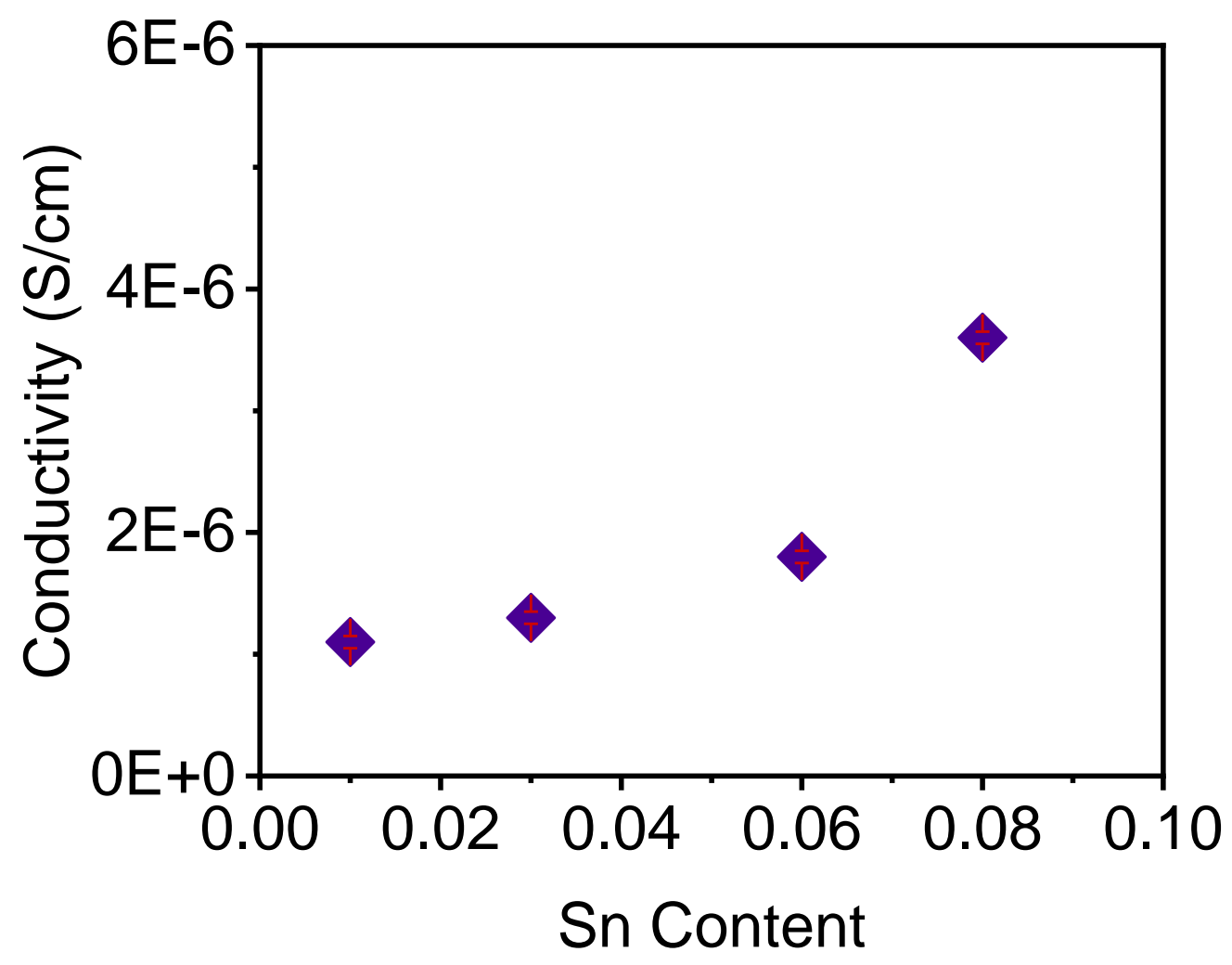

Figure S18. A plot illustrating the electrical conductivity vs. Sn composition of $\sim 200 \mathrm{~nm} \mathrm{Ge} e_{-x} \mathrm{Sn}_{\mathrm{x}}$ thin films. The films were fabricated by spin coating a formamide solution of alloy QDs. 


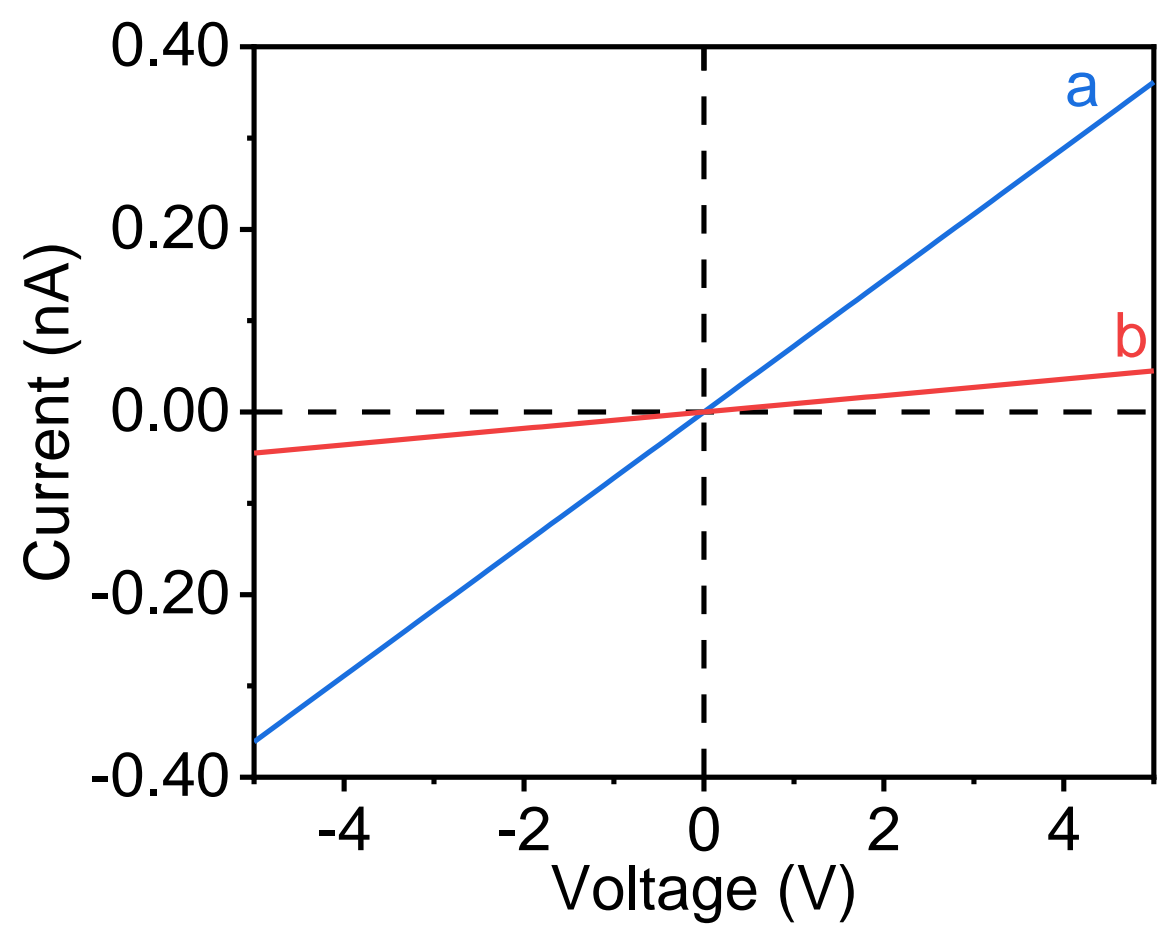

Figure S19. Current-voltage (I-V) measurements of (a) a freshly prepared $200 \mathrm{~nm}$ MCC-capped $\mathrm{Ge}_{0.92} \mathrm{Sn}_{0.08} \mathrm{QD}$ thin film along with (b) the film that has been exposed to air for 6 months. A decrease in conductivity from $3.6 \times 10^{-6} \mathrm{~S} \mathrm{~cm}^{-1}$ (as-prepared) to $4.5 \times 10^{-7} \mathrm{~S} \mathrm{~cm}^{-1}$ (6 months old) occurred likely due to formation of $\mathrm{GeO}_{2}$ impurities. 


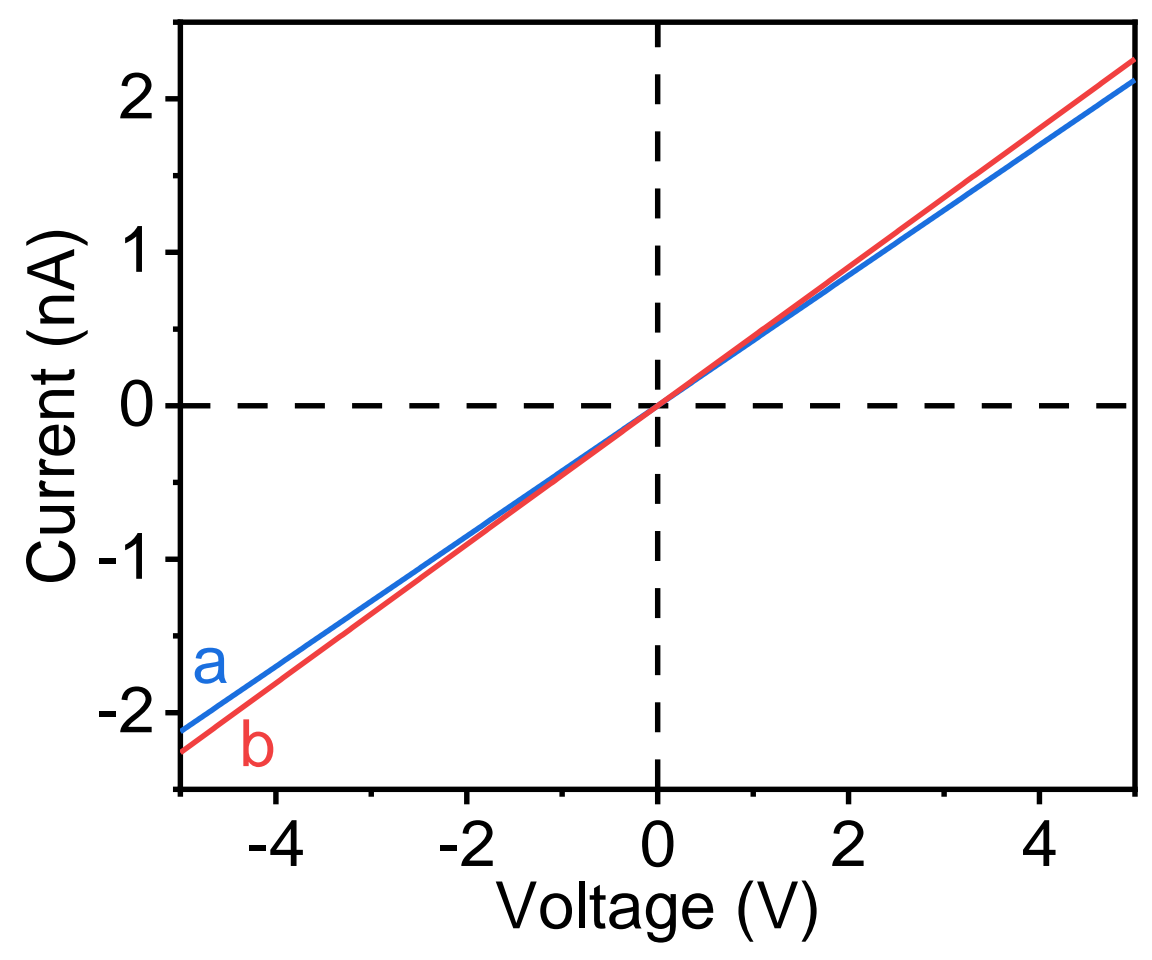

Figure S20. Current-voltage (I-V) measurements of a 200 nm MCC-capped $\mathrm{Ge}_{0.94} \mathrm{Sn}_{0.06}$ QD thin film with conductivity measurements taken (a) in the dark and (b) under ambient fluorescent light. A slight increase in conductivity is noted under ambient fluorescent light indicating a photoresponse from the QD thin film. 